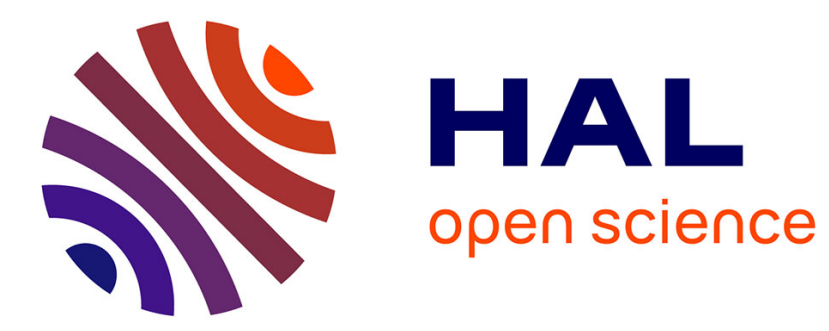

\title{
Morphology of InGaAs/InP QWs : from excitonic spectroscopy to HR-TEM analyses
}

J. Camassel, S. Juillaguet, R. Schwedler, K. Wolter, F. Baumann, K. Leo, J. Laurenti

\section{- To cite this version:}

J. Camassel, S. Juillaguet, R. Schwedler, K. Wolter, F. Baumann, et al.. Morphology of InGaAs/InP QWs: from excitonic spectroscopy to HR-TEM analyses. Journal de Physique IV Proceedings, 1993, 03 (C5), pp.C5-99-C5-106. 10.1051/jp4:1993518 . jpa-00251604

\section{HAL Id: jpa-00251604 https://hal.science/jpa-00251604}

Submitted on 1 Jan 1993

HAL is a multi-disciplinary open access archive for the deposit and dissemination of scientific research documents, whether they are published or not. The documents may come from teaching and research institutions in France or abroad, or from public or private research centers.
L'archive ouverte pluridisciplinaire HAL, est destinée au dépôt et à la diffusion de documents scientifiques de niveau recherche, publiés ou non, émanant des établissements d'enseignement et de recherche français ou étrangers, des laboratoires publics ou privés. 


\title{
Morphology of InGaAs/InP QWs: from excitonic spectroscopy to HR- TEM analyses
}

\author{
J. CAMASSEL, S. JUILLAGUET, R. SCHWEDLER* ${ }^{*}$ K. WOLTER*, F.H. BAUMANN**, K. LEO* \\ and J.P. LAURENTI***
}

GES, Université de Montpellier II, 34095 Montpellier cedex 5, France

* Institute of Semiconductor Electronics II, RWTH, 5100 Aachen, Germany

** AT\&T Bell Labs., Holmdel, NJ 07733, U.S.A.

*** CLOES-SUPELEC, Université de Metz, 57078 Metz cedex 3, France

\begin{abstract}
We report on the non-squared composition profiles of three series of thin $\left(\mathbf{L}_{\mathbf{z}}<30 \AA\right) \operatorname{InGaAs} / \mathrm{InP}$ quantum wells grown with interruption sequences at, both, the lower and the upper interfaces. First is a series of LM (lattice matched) samples with nominal thicknesses ranging from 0 to 8 monolayers. Second is a series of samples with a constant thickness of 5 monolayers and gallium compositions ranging from 0.13 to 0.73 . Third are two samples with thickness $L_{z}=30 \AA$ and gallium compositions $x=0.47(\mathrm{LM})$ and $\mathrm{x}=0.73$ (gallium rich). Comparing spectrometric data collected at $2 \mathrm{~K}$ with high-resolution transmission electron microscope (HR-TEM) pictures, we find that the lower interface morphology (InP/InGaAs) can be easily probed from excitonic absorption and luminescence spectra. Nothing similar is found for the higher interface (InGaAs/InP), even if a considerable amount of interface roughness is resolved from HR-TEM. We show that this upper interface roughness originates from unperfected 2-dimensional growth kinetics of InGaAs.
\end{abstract}

\section{Introduction}

For many years InGaAs quantum wells (QWs), lattice matched to InP, have attracted very much interest for optical device applications. As a consequence, in the range of $85 \AA$ thickness (which is typical of $1.55 \mu$ devices and maximum transmission of the optical fibers), the control of the growth parameters is (more or less) a matter of routine. The resolution of sharp excitonic features (even at room temperature) has become a standard [1] and, recently, they have been shown to provide convenient tools for the fast characterization of wells composition and thickness [2].

In the range of $1.3 \mu$ (which corresponds with minimal dispersion of the optical fibers), the situation is entirely different. Very thin QWs must be grown (the typical thickness being now 8 monolayers) and only a few monolayers (MLs) departure from the nominal value is a major drawback. With this respect, both the control of quantum well thickness and interface morphology are necessary to achieve reproducible results. Since ultra-thin QWs and superlattices (SLs) have active layers made of 2-dimensional (2-D) terraces with MLs well width fluctuations [3], increasing the interface abruptness is nothing but reducing the size of the atomic steps fluctuations. Basically, two possibilities exist. The first one is atomic layer epitaxy (or ALE). The second is to use growth interruption sequences (or GIS). Using ALE, the active parts of the devices would be grown atomically (layer by layer) and should be intrinsically flat (ideally, the interfaces should be defect-free). Using a GIS, one expects to increase the size of the natural (as-grown) 2-D islands (in plane $\mathrm{Lx}$ and Ly dimensions) by allowing the different 
interfaces to relax. This is nothing but averaging over neighbouring (different) values of $\mathrm{Lz}$. Concerning the specific effect of a GIS on the stoichiometry of the interface, not much is really known $[3,4]$ and it is not clear to decide how deep they affect the final QW profile.

In this work, we concentrate on thin multiple quantum wells (MQWs) of InGaAs $\left(\mathrm{L}_{\mathrm{z}}<30 \AA\right)$ separated by thick $(300 \AA)$ InP barriers. Two different GIS have been done according to the schematic drawing shown in Fig. 1. They lasted for $5 \mathrm{~s}$. at the lower (direct) InP/InGaAs interface and for $3 \mathrm{~s}$. at the upper (inverse) InGaAs/InP one. Details of the growth procedure can be found in refs. 5, 6 and additional series of experimental results in the works of refs. 5-13.

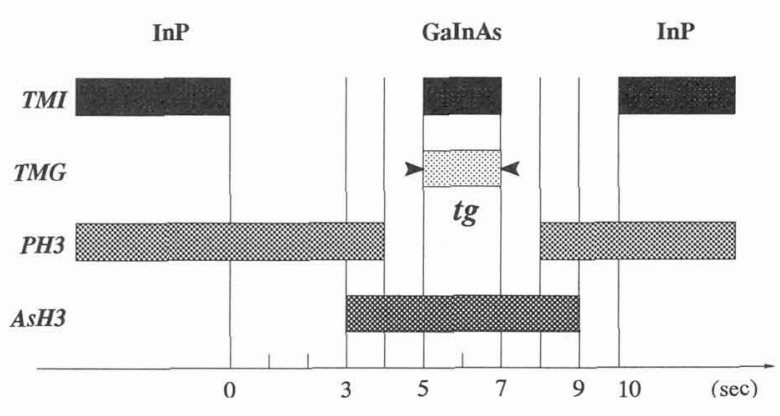

Fig. 1: Details of the growth interruption sequences used to grow the series of InGaAs/InP MQWs investigated in this work.

\section{Monolayer energy splitting}

We show, in Fig. 2, the PL spectra collected at $2 \mathrm{~K}$ on the first series of samples (nominal gallium composition $x=0.47$ ). For clarity, we specify every time the nominal thickness estimated from the growth run (finite number of MLs) and indicate the theoretical energy position of the corresponding $\mathrm{E}_{1}, \mathrm{HH}_{1}$ transition.

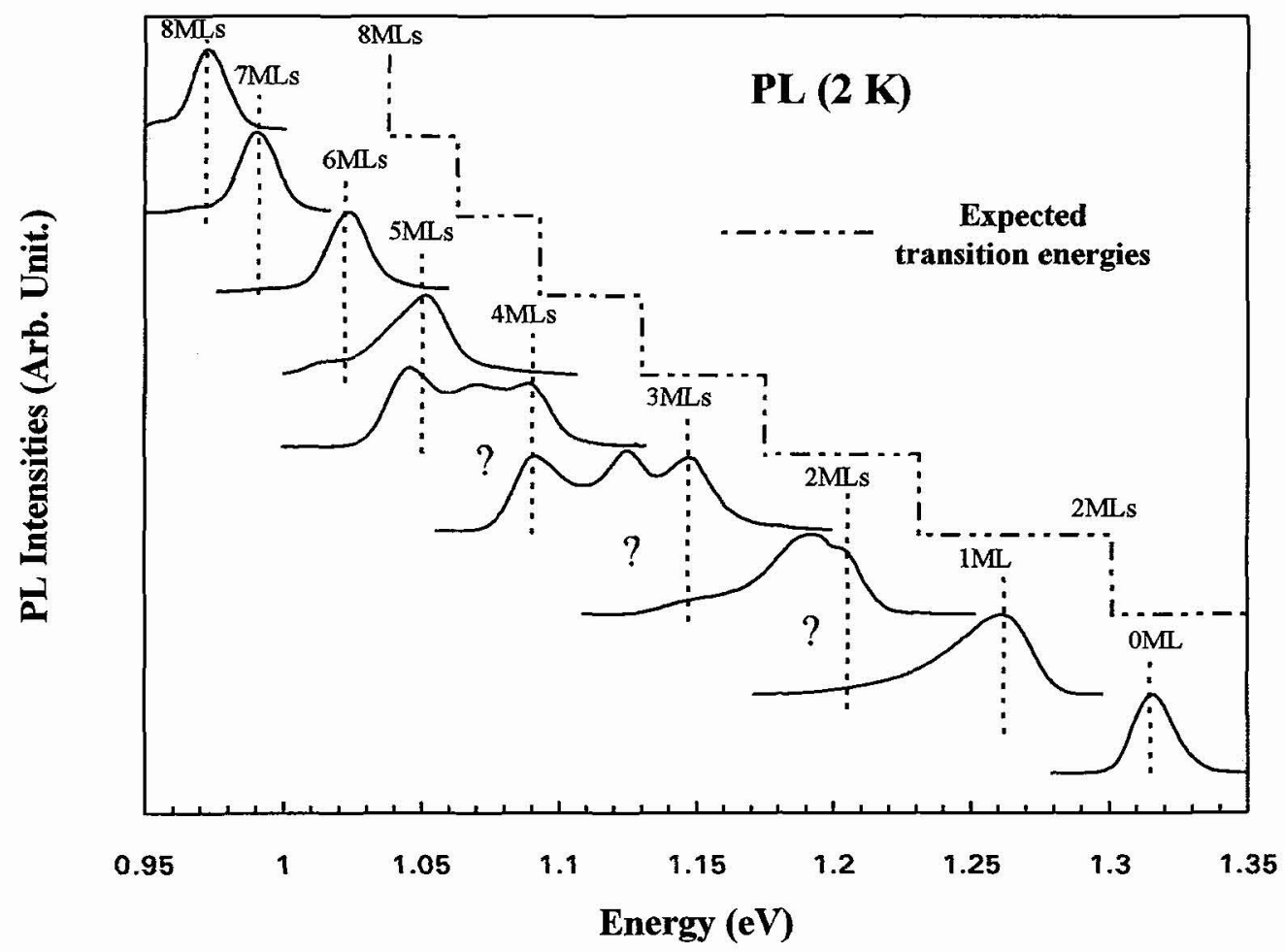

Fig. 2: PL spectra collected at $2 \mathrm{~K}$ on a series of samples with nominal gallium composition $\mathrm{x}=0.47$ but different (integer) values of well thickness. 
Two points should be emphasized. First, we find a clear effect of ML energy splitting with (more or less) well identified "a priori" structures. This has been similarly reported in many works (see, for instance ref. 3) and is generally taken as strongly indicative of a "perfect" 2-D mode of growth [5]. However, even in case, two problems remain. The first one is that none of the "a priori" identifications agree well with each other and/or with simple theoretical estimates. The second is that one finds additional peaks (extra features indicated by question marks) which show that no simple identification can hold for all experimental lines. Either alloy fluctuations from well to well or additional (interface) contributions must be called for. In our case, alloys fluctuations have been ruled out from systematic controls performed every 10 runs on bulk reference layers [5] and, moreover, could not account for the zero ML feature shown around $1.315 \mathrm{eV}$. As a consequence only interface contribution will be considered.

\section{Direct interface morphology}

As already said, when no active layer of InGaAs is deposited ( $t_{g}=0$ in Fig. 1), one collects the zero ML signal displayed in Fig. 2. This is now a well understood evidence [14] of excitons bound to interface wells which, at least, may have two different origins. First is an effect of arsenic atoms substituting for phosphorus at the free surface of InP exposed to arsine flux during the GIS. This concerns only the last few MLs deposited before interruption and constitutes really what should be called the lower interface well. Second is an effect of incomplete arsine purge after the GIS has been finished (memory effect). This should result more in InAsP-like top barriers $[15,16]$. To what extend these InAsP-like top barriers are also associated with a pure InAs-like upper interface well is still unclear. The first problem is to decide whether these interface layers are homogeneous and repetitive or not and, then, what is their chemical composition.
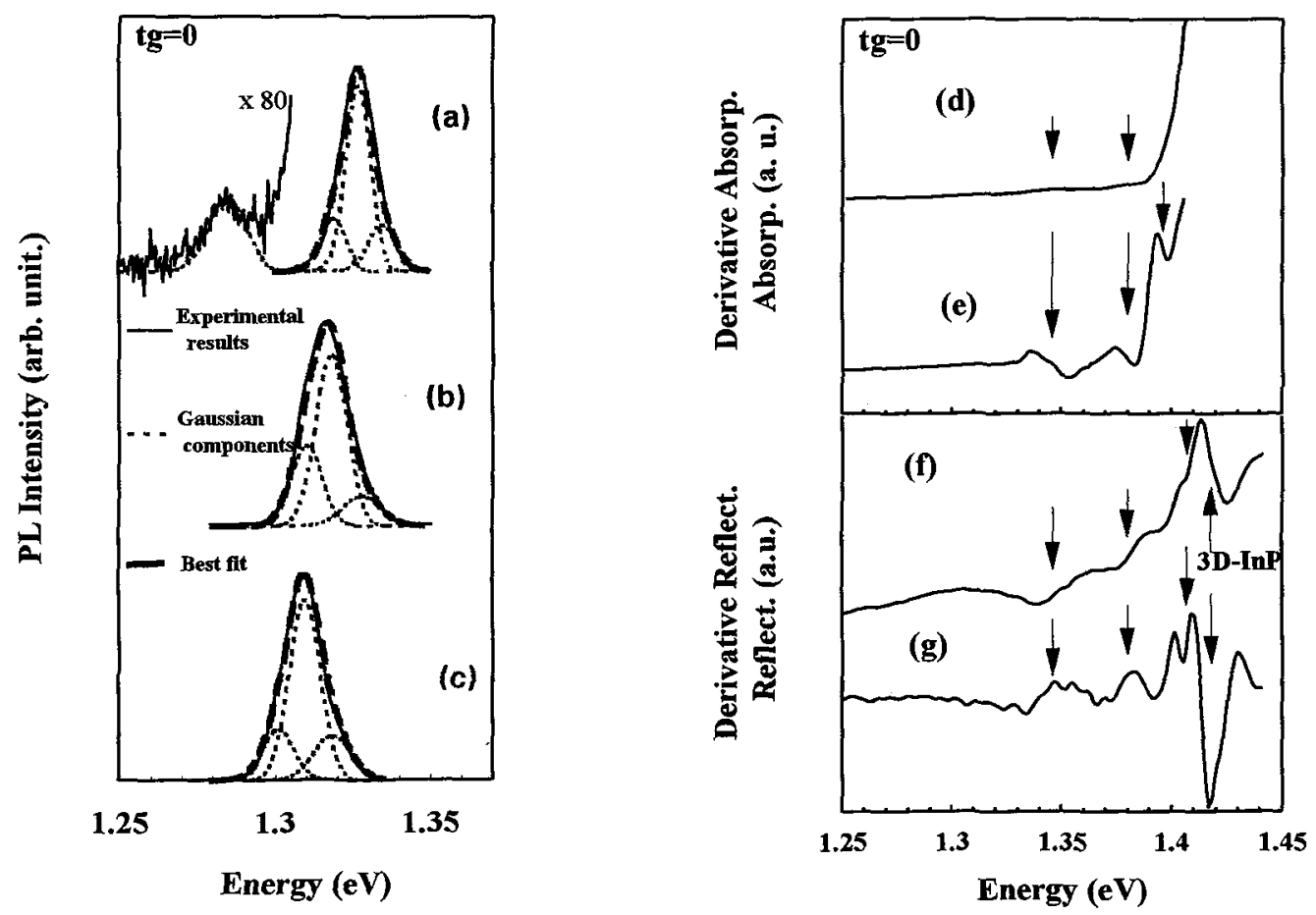

Fig. 3: Optical properties of excitons bound to interface-wells in the case of $\operatorname{InP} / \operatorname{InP}(2 \mathrm{~K})$ :

$(a, b, c)$ PL measurement;

(d, e) absorption and derivative absorption,

$(f, g)$ reflectivity and derivative reflectivity spectra. 
Consider, first, the series of PL spectra $((2 \mathrm{~K})$ displayed in Figs. 3a to $3 \mathrm{c}$. They demonstrate, without ambiguity, that the interface wells (composition and/or thickness) vary slightly over a sample area. Moreover, comparing with (d) absorption, (e) derivative absorption, (f) reflectivity and (g) derivative reflectivity spectra also collected at $2 \mathrm{~K}$, one finds that the interface structure which is experimentally resolved depends on the nature of the optical probe which has been used. PL focuses more on InAs-rich islands than absorption spectroscopy.

To account quantitatively for the experimental values of the confinement energies, we must take into account the finite effect of in-situ diffusion (intermixing). This appears during the final part of the growth run. Toward this end, we have combined a ML by ML approach with a Green function technique and a transfer matrix method [11-13] to analyse the interband absorption and recombination energies. We find that, in the limiting case $\operatorname{tg}=0$, the final (real) interface observed in PL originates from 1.5 to $2 \mathrm{MLs}$ of pure InAs. After insitu diffusion, it extends over, typically, 4 to $5 \mathrm{MLs}$.

While it is now clear that, after a GIS, a finite interface structure develops, it is not obvious that the same interface layers reproduce exactly from GIS to GIS. To clarify this point, we have collected X-ray diffraction spectra on an InP/GIS/InP sample [12]. The results are shown in Fig. 4. They show that (at least in our case) the periodic GIS have a signature in X-ray diffraction ; We emphasize again that no InGaAs QW was intentionally grown and that only 10 GIS had been managed under arsine between 11 InP runs. This resulted clearly :

i) in 10 interfacial QWs separated by $230 \AA$ barriers (instead of a nominal value of $300 \AA$ );

ii) in a persistent memory effect which explains (over a period) the average composition $\operatorname{InAs}_{0.0155} \mathrm{P}_{0.9845}$ (instead of pure InP).

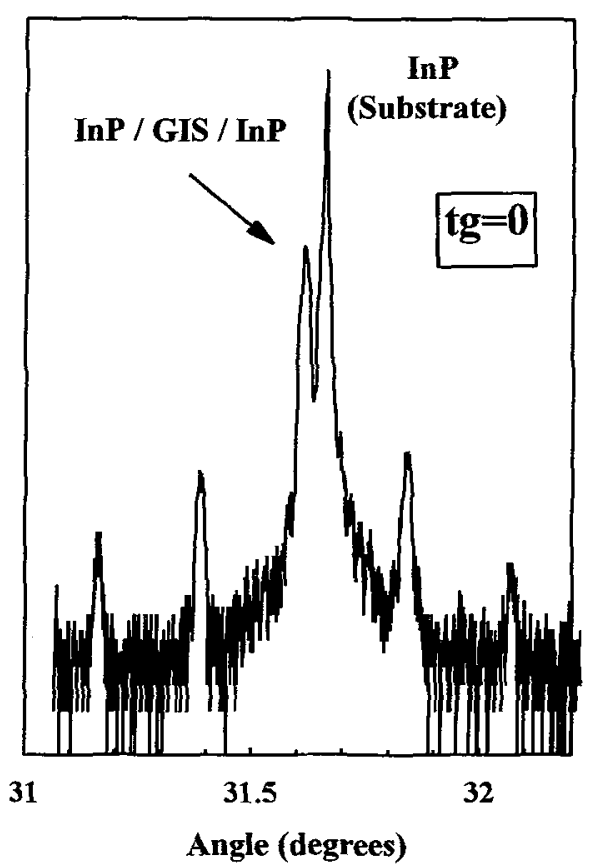

Fig. 4: DDX spectrum collected on an InP/InP sample grown without any InGaAs active layers. In this case only 10 GIS had been alternated with the growth of the InP layers.

\section{Thickness dependence}

Up to now we have found that, in our samples, finite interface layers developed after a GIS. Since both arsenic exchanging for phosphorus and arsenic memory effects have been evidenced, the point is now to try to split the two components. Toward this end, we have investigated the thickness dependence of both absorption and luminescence features. The results are show in Figs. $5 \mathrm{a}$ and $5 \mathrm{~b}$, respectively, and confirm the results of our previous investigation.

Performing a detailed comparison with our theoretical model, we find the following :

i) When considered through the complete series of samples, the energetic positions of the absorption lines confirm that the last $\mathrm{ML}$ of InP ( $+/-0.5 \mathrm{ML}$ ) was exchanged (before intermixing) by an interface layer made of pure InAs. This is similar to the results found for the sample grown with $\mathrm{tg}=0$. Adding now to the nominal thickness of InGaAs, this gives (after intermixing) a first series of compositional islands. Because these compositional domains have pretty large dimensions with respect to the Bohr radius of the excitons, the monolayer energy splitting is easily resolved. In this case, the growth time acts only to 
modify the relative repartition of intensity from line to line (i.e. from one nominal thickness to the next one). Versus growth time, this gives the experimental series of plateaux shown in Fig. 5a.

ii) Concerning PL, the same mechanism arises but the experimental energy positions support better a recombination of excitons originating from a second series of islands. These are made of 1.5 to $2 \mathrm{MLs}$ of InAs (initial coverage) which, again, add to the nominal InGaAs layer. In this case, the ML splitting can still be resolved [5-7], even if the thickness dependence of the optical spectra displayed in Fig. 5b appears intermediate between step-like and continuous.

iii) Concerning the upper interface morphology, up to now, no evidence could be found.

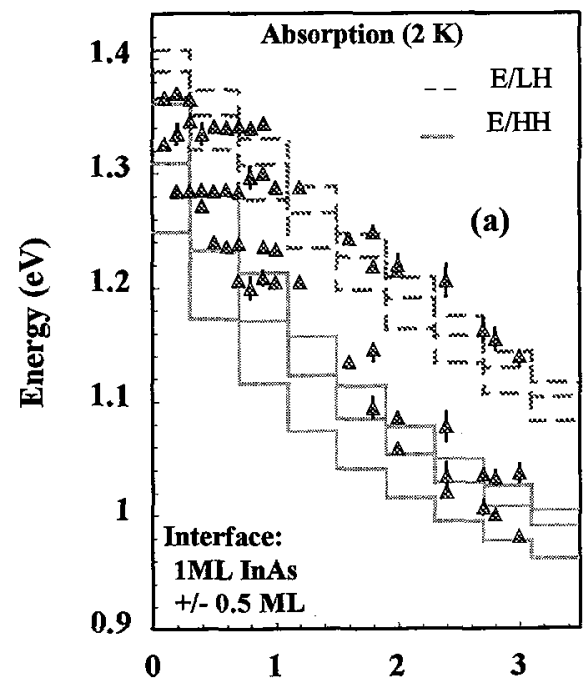

Growth time (seconds)

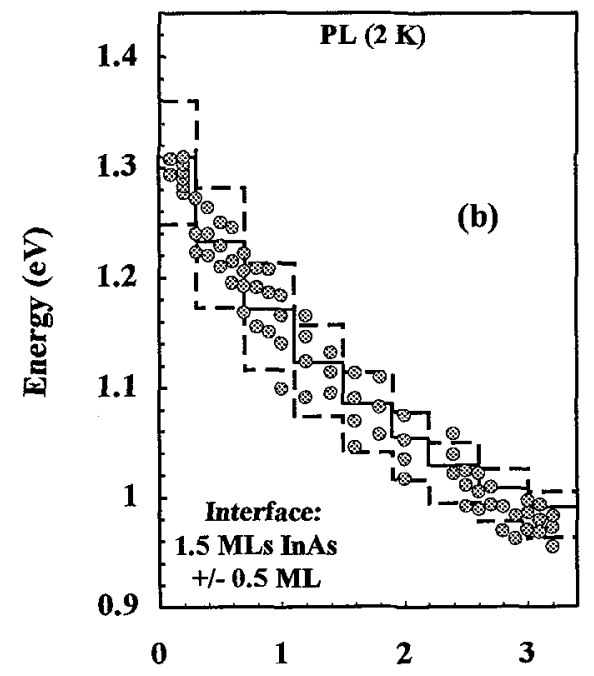

Growth time (seconds)

Fig. 5: Comparison of experimental results with our theoretical predictions in the case of a) absorption and b) PL measurements performed versus thickness.

\section{Compositional dependence}

In a second series of experiments, we have used a constant (nominal) thickness of $5 \mathrm{MLs}$ to investigate the composition dependence of the PL lines. In this series of samples, the gallium composition ranged from $x=0.17$ to .73 and was determined by SNMS (sputtered neutral mass spectroscopy). For

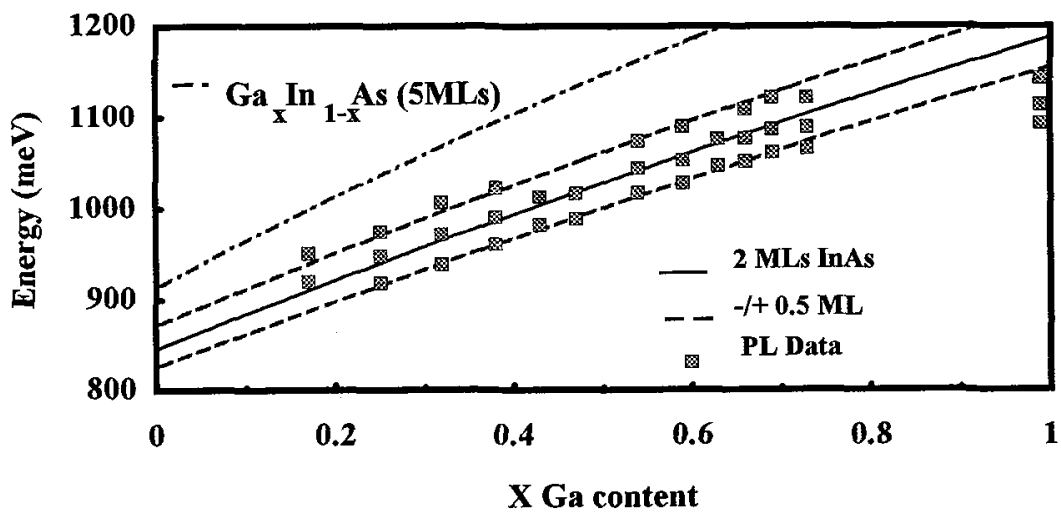

Fig. 6: Composition dependence of the PL-lines versus gallium content. The theoretical computation includes only nominal values and 2 MLs InAs at the lower interface (see text). 
completeness, a special sample with $\mathrm{x}=1$ (pure GaAs/InP case) was also grown.

Versus composition, we resolve a threefold structure which spans almost entirely the entire composition range. This is shown in Fig. 6 . Again, none of the lines agree with the standard predictions of the simple square well model (dot-dashed line) but, on the opposite, give evidence of an interfacial origin.

This is demonstrated, first, in Fig. 7. We compare two different PL spectra collected at $2 \mathrm{~K}$.

First is a SQW and, second, a MQW with identical gallium compositions. In both cases, we find a manifold structure which exhibits, roughly speaking, the same three components. (They are, simply, shifted to higher energy in the case of the MQW because there is more phosphorus diffusing into the well, i.e. more intermixing).

To compute the theoretical energy positions displayed in Fig. 6, we work along the path of section 4 . We assume that, whatever is the gallium composition, 1 to $2 \mathrm{MLs}(+/-0.5 \mathrm{ML})$ of $\mathrm{InP}$ are originally saturated with arsenic at the lower interface. Then, combining with $5 \mathrm{MLs}$ of $\operatorname{In}_{\mathrm{x}} \mathrm{Ga}_{1-\mathrm{x}}$ As (nominal well thickness) and two InP barriers, we get different series of PL lines. The interesting point is that, again, a very satisfactory fit is obtained with about $2 \mathrm{MLs}$. In this case, changing simply the gallium composition, we predict for the composition dependence of the 3 lines, the results shown in Fig. 6. Obviously, the agreement is very satisfactory and supports our simple viewpoint.

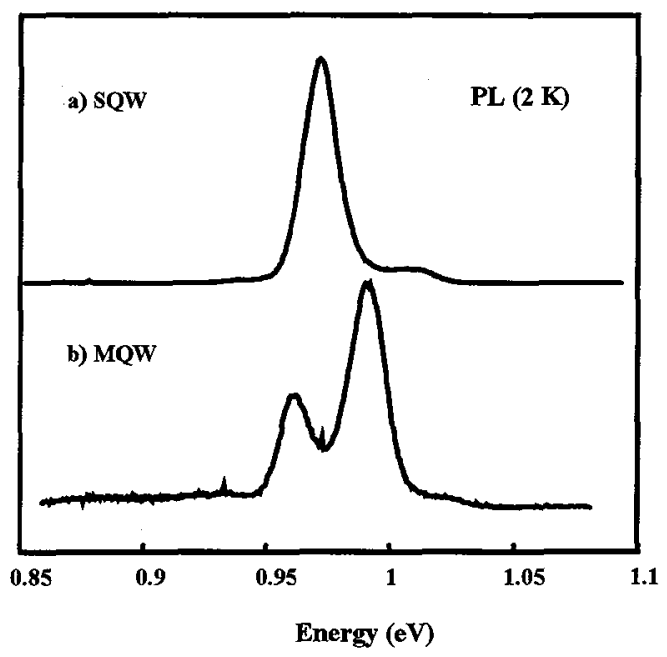

Fig. 7 : Manifold structure observed in this work for a) a single and b) a multiple $Q W$ of InGaAs/InP with identical gallium composition $(x=0.38)$. The high energy shift noticed in Fig. $7 \mathrm{~b}$ comes from deeper in-situ diffusion with more phosphorus moving from the barriers into the wells.

\section{TEM data and analysis}

Up to now, we have found that the same mechanism of arsenic incorporation and diffusion could explain, by mean of a few additional layers, all data collected versus composition and thickness. No evidence of upper interface was found and, simply, a slightly more important initial coverage ( 2 MLs instead of 1.5) could evidence, in the case of the strained samples could evidence some strain sensitivity. To get confirmation on this point we have performed HR-TEM measurements.

Two different samples have been investigated. They had nominal thicknesses of $10 \mathrm{MLs}$ of InGaAs and corresponded with gallium compositions $x=0.47$ (Fig. 8, LM) and $x=0.73$ (Fig. 9, gallium rich). The TEM pictures were taken in the chemical lattice imaging mode (Fig. 8a and 9a) and analyzed using the vector pattern recognition technique $[4,17]$. The resulting symmetry profiles are shown in Figs. $8 \mathrm{~b}$ and $9 \mathrm{~b}$, respectively. The most striking feature is a strong asymmetry of the two interfaces which increases from the LM to composition to the Ga-rich sample. While the lower one (InP/InGaAs) appears sharp, the upper one (InGaAs/InP) shows a considerable roughness. This is not an effect of GIS but comes from imperfect 2-dimensional mode of growth. This exists already on the lattice matched sample but becomes more pronounced on straining the QWs.

For completeness, we plot also in Figs. $8 \mathrm{~b}$ and $9 \mathrm{~b}$ the results of a simple computation (open squares) where we use a statistic distribution of InGaAs thicknesses (centered around a nominal value) before in situ diffusion : 
using :

$$
\left\langle\mathrm{P}_{\mathrm{M}}\right\rangle=\frac{1}{\sigma_{\mathrm{p}} \sqrt{2 \pi}} \mathrm{e}^{-\frac{\left(\mathrm{M}-\mathrm{M}_{0}\right)^{2}}{2 \sigma_{\mathrm{p}}^{2}}}
$$

i) $M_{0}=10$ MLs and $\sigma_{\mathrm{p}}=2$ for $\mathrm{x}=0.47$;

ii) $\mathrm{M}_{0}=9 \mathrm{MLs}$ and $\sigma_{\mathrm{p}}=4$ for $\mathrm{x}=0.73$, we find a very satisfactory agreement between our average composition profiles and the experimental HR-TEM determinations (full dots).
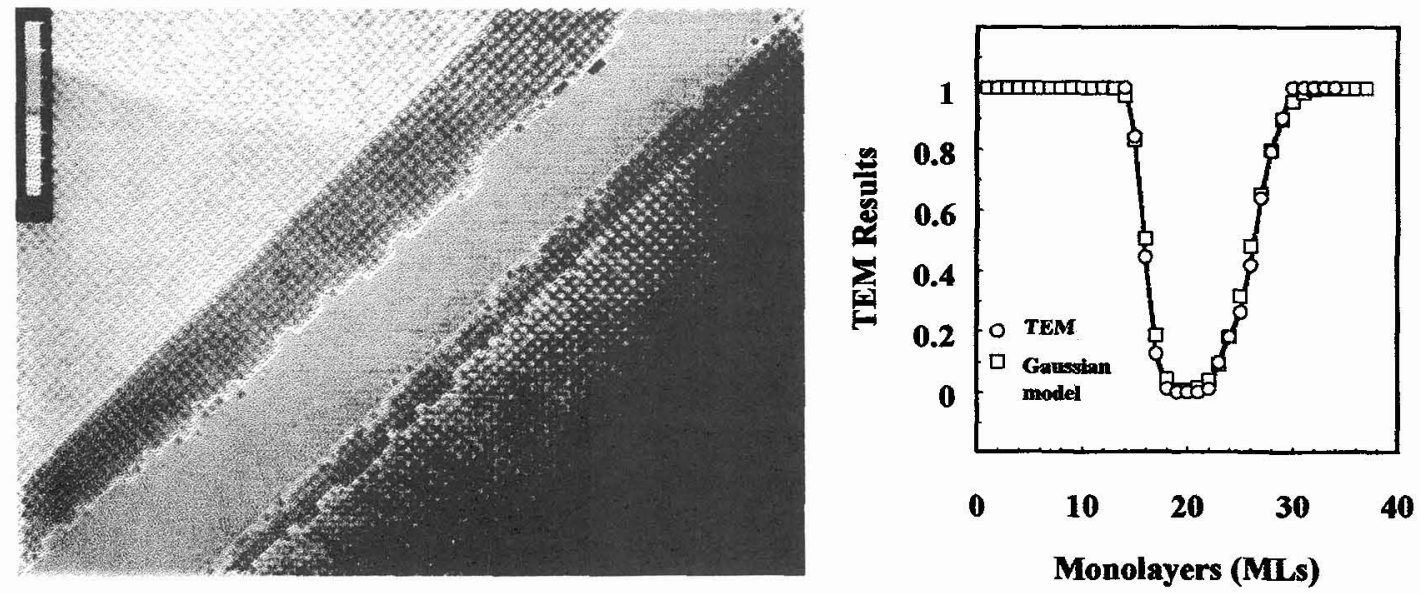

Fig.8: a) Chemical lattice image deduced from HR-TEM measurements in the case of a lattice-matched InGaAs sample $(\mathrm{L} z=30 \AA)$; b) comparison of the corresponding symmetry profile (full dots) with the composition profile obtained in this work assuming a Gaussian distribution of QW thickness (see text).
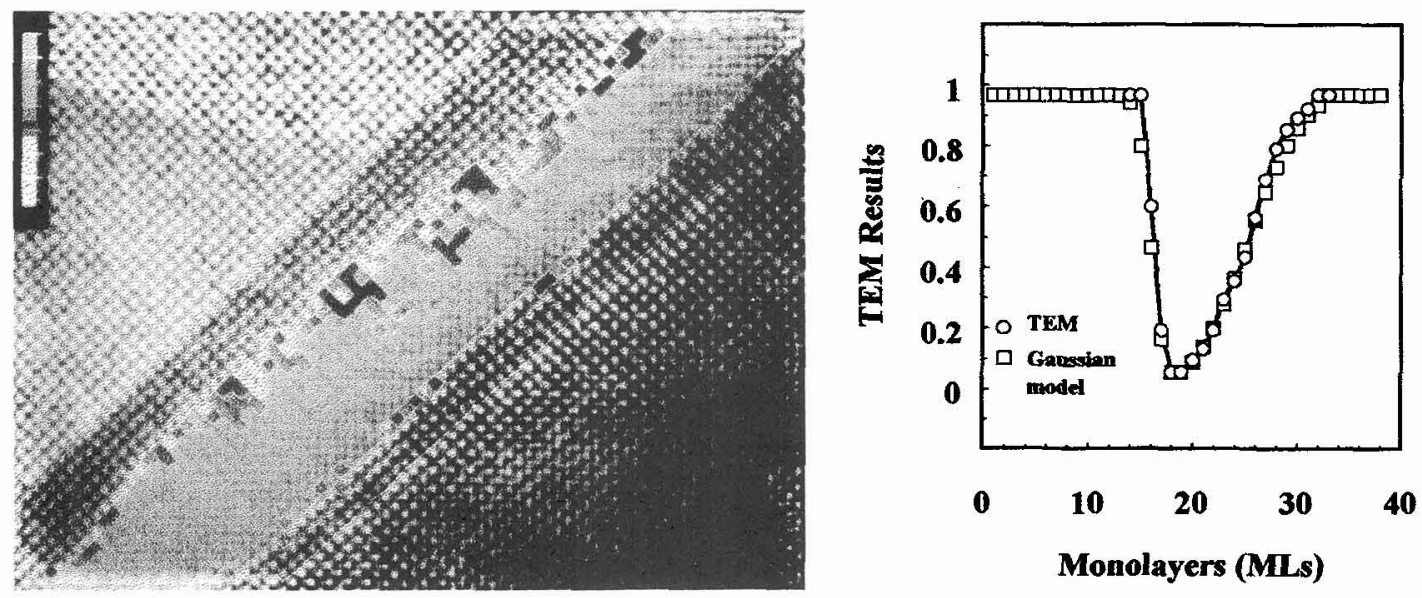

Fig. 9: Same as Fig. 8 in the case of a gallium rich sample $(x=0.73)$. Notice the composition dependence of the upper interface roughness. It comes from less 2-dimensional growth kinetics (see text). 


\section{Conclusion}

Performing systematic investigation of a series of MQWs grown with different thicknesses and compositions, we have shown that the lower interface morphology can be easily probed from excitonic spectroscopy. Nothing similar is found concerning the upper interface, even if a considerable amount of roughness exists. We have shown that this upper interface roughness comes only from unperfected 2-dimensional growth kinetics of InGaAs.

\section{References}

[1] see, for instance: M. Sugawara, T. Fujii, Y. Yamazaki and K. Nakajima; Phys. Rev. B42, 9587 (1990) and references therein.

[2] J.P. Laurenti, J. Camassel, B. Reynes, D. Grützmacher, K. Wolter and H. Kurz; Semicond. Science and Technology 5, 222 (1990).

[3] for a recent review, see : M.A. Herman, D. Bimberg and J. Christen; J. of Applied Physics 70, R1 (1991) and references therein.

[4] A. Ourmazd, NATO ASI Series B281, 123 (1991).

[5] D. Grützmacher, J. Hergeth, F. Reinhardt, K. Wolter and P. Balk; J. Electron. Mater. 19, 471, (1990).

[6] J. Hergerth, D. Grützmacher, F. Reinhardt and P. Balk; J. of Crystal Growth 107, 537 (1991); also see: D. Grützmacher; Journal of Crystal Growth 107, 520 (1991).

[7] R.Schwedler, F.Reinhardt, D. Grützmacher and K. Wolter; Journal of Crystal Growth 107, 530 (1991).

[8] J. Camassel, J.P. Laurenti, S. Juillaguet, F. Reinhardt, K. Wolter, H. Kurz and D. Grützmacher; Journal of Crystal Growth 107, 543 (1991).

[9] R. Meyer, H. Hardtdegen, R. Carius, D. Grützmacher, M Stollenwerk, P. Balk, A. Kux and B. Meyer; J. Electron. Mater. 21, 293 (1992).

[10] R. Kersting, R. Schwedler, K. Wolter K. Leo and H. Kurz; Phys. Rev. B46, 1639 (1992).

[11] S. Juillaguet, J.P. Laurenti, R. Schwedler, K. Wolter, J. Camassel, and H. Kurz; "Non stoichiometry in semiconductors" (Elsevier, 1992), p.155.

[12] S.Juillaguet, R.Schwedler, A.Kohl, F.H.Baumann, B.Fraisse, J.Camassel, K.Wolter, K.Leo, B.Gallmann, M.Stollenwerck and J.P.Laurenti; Proc. 5th InP and related materials" (IEEE cat.\#93CH3276-3), Paris (1993) p.301.

[13] J. Camassel, K. Wolter, S. Juillaguet, R. Schwedler, E. Massone, B. Gallmann, and J.P. Laurenti; Materials Sciences and Eng. B: Solid State Material for Advanced Technology, (in press).

[14] see, for instance, T.Y. Wang, K.L. Fry, A. Persson, E.H. Reihlen and G.B. Stringfellow, J. Appl. Phys 63, 2674 (1988).

[15] F.Genova, A.Antolini, L.Francesio, L.Gastaldi, C.Lamberti, C.Papuzza and C.Rigo; J. of Crystal Growth 120, 333 (1992).

[16] G.Landgren, J.Wallin and S.Pellegrino; J. Electron. Mater. 21, 105, (1992).

[17] see, for instance, J. Kim, J.J. Alwan, D.V. Forbes, J.J. Coleman, I.M. Roberson, C.M. Wayman, F.H. Baumann, M. Bode, Y. Kim and A. Ourmazd, Appl. Phys. Lett. 61, 28 (1992), and references therein. 